\title{
AN EXPLORATION INTO PEOPLE'S PERCEPTION AND INTENTION ON USING CRYPTOCURRENCIES
}

\author{
Jake McMORROW ${ }^{1 *}$ \\ Mona SEYED ESFAHANI²
}

Received: July 2021 | Accepted: August 2021 | Published: August 2021

Please cite this paper as: McMorrow, J., Seyed Esfahani, M. (2021) An exploration into people's perception and intention on using cryptocurrencies, Holistica Journal of Business and Public

Administration, Vol. 12, Iss. 2, pp.109-144

\begin{abstract}
The cryptocurrency market has been described as revolutionary due to the constant technological evolution and innovation that the blockchain technology provides. Leading many to believe that this could be the next step for the human race, just like how fiat currency replaced gold. Cryptocurrencies were originally created to be a form of savings or income for the unbanked, reduce costs and energy consumption, for a means of data transparency and to remove financial intermediaries. It is undeniable that the cryptocurrency market has created a divide of opinions, as some look to explore the market further while others reject the thought of adopting this innovative technology completely. This study focuses on the perception and intention to use cryptocurrencies. Diving into previous literature about the adoption of cryptocurrencies and new technologies. Highlighting key factors that can affect an individual's perception and gaps in the literature that need to be explored further. A quantitative approach was used to gather data from 102 participants. The findings indicated that performance and effort expectancy as the most influential variables for cryptocurrency adoption, as people seek understanding as what benefits cryptocurrencies can provide for them when they feel incapable of using the innovative technology.

Keywords: Cryptocurrency; Perception, Intention, Technology; Innovation
\end{abstract}

\section{Introduction}

A cryptocurrency is essentially a form of digital or virtual currency that is impossible to counterfeit or double-spend, due to the currencies decentralized networks that are based on blockchain technology (Schaupp, 2018). The cryptocurrency market is a dynamic industry, that is very innovative as it consistently develops or improves new technology.

\footnotetext{
${ }^{1}$ Faculty of Business School, Bournemouth University, Fern Barrow, Poole BH12 5BB, Bournemouth, United Kingdom, e-mail: jakemcmorrow911@gmail.com

* Corresponding author

${ }^{2}$ Faculty of Media and Communication, Bournemouth University, Fern Barrow, Poole BH12 5BB, Bournemouth, United Kingdom, e-mail: mseyedesfahani@bournemouth.ac.uk
} 
Many experts believe that cryptocurrency cannot be stopped, and its inevitability going to become the 'gold standard' (Carson et al., 2018; Schaupp, 2018; Deloitte, 2015).

The birth of Bitcoin in 2009 would be the start of the cryptocurrency market and a new finance counterculture. At this point Bitcoin didn't have a tangible value and was used to reward others for their comments in certain forums (Simonite, 2011). The first recorded "real" transaction was in 2010, the purchase of two pizzas for 10,000 Bitcoin. At the time, the value of the two pizzas would be $\$ 30$, however the next 11 years would see Bitcoin's price and value drastically rise. As of today (10/02/21) one Bitcoin is worth around $\$ 45,000$, which effectively means the value of those pizzas with the inflated price applied is $\$ 450$ million (Ledger, 2019). This highlights the astronomical rise of value of Bitcoin and the cryptocurrency market.

Since the birth of Bitcoin, the cryptocurrency market is much more diverse and in just over a decade there are now more than 6000 forms of cryptocurrencies, known as 'coins', available (Hileman \& Rauchs, 2017). The evolution of the cryptocurrency market has seen the total market cap to be valued at over \$1trillion (CoinGecko, 2021), in comparison to the gold market, the cryptocurrency market is only worth roughly $10 \%$ of the gold market (Business Insider, 2021). Many experts predict that the cryptocurrency market will continue to grow and exceed the market cap of Gold (Carson et al., 2018; Schaupp, 2018; Deloitte, 2015).

As previously stated, the cryptocurrency market has been a catalyst for technological advancement. A significant event of this was the introduction of Ethereum. Ethereum were one of the first cryptocurrencies to implement smart contracts and ERC tokens, so that an ecosystem could run on their blockchain and host its own native currency at the same time (Ledger, 2019). Smart contracts have been labelled as the replacement of lawyers. This is because smart contracts are a computer code that can verify, facilitate, and enforce the agreement of a contract while being stored on the blockchain based platform (Harvard Law, 2018). A blockchain's decentralized system allows smart contracts to effectively reduce time and expenses by not involving a 'middleman'. Including the use of smart contracts, Ethereum's application of ERC tokens was able to give the ability of other cryptocurrencies to run on Ethereum's blockchain, without the need of their own blockchain network to be developed.

Currently in society cryptocurrencies have started to become adopted by mainstream markets. An example of this is JP Morgan's confidence of Bitcoin to continue its price surge, as the possibility of one Bitcoin reaching six figures is becoming more realistic. This was supported by the fact that PayPal would allow their users to perform transactions, whether it was selling or buying, with the use of Bitcoin (Bambrough, 2020). Then in February 2021, Elon Musk announced the $\$ 1.5$ billion acquisition of Bitcoin, and that Tesla would be the first automaker to accept Bitcoin as payment for their vehicles (CBNC, 2021). This shows the progress Bitcoin has made to become a more orthodox currency, but with this progress there are still doubters and implications for Bitcoin and other cryptocurrencies to become fully adopted in society. Current US Treasury Secretary, Janet 
Yellen, has proposed increasing capital gains tax and implementing an unrealised capital gains tax (Mohsin \& Condon, 2021). Proposing capital gains tax on potential profit that hasn't been cashed in yet could cause a downfall for cryptocurrencies by causing a considerable drop of the investment into the cryptocurrency market. However, this would also cause investment in regular stocks and other investment avenues to be less enticing and likely for investors to venture into other foreign markets. This has already been seen as foreign institutional investors have ploughed $\$ 20$ billion into the Indian market, since the start of 2021 (Business Insider, 2021). In addition, the Spanish Government approved a bill that forces their population to disclose any cryptocurrency holdings as they look to tackle tax avoidance (Bitcoin, 2020).

As some governments, companies and investors are starting to accept the use of cryptocurrencies and others are strongly rejecting, it is hard to determine the perception and acceptance of the mass population. Therefore, understanding how cryptocurrencies is perceived by the mass population is vital to comprehend the potential success and adoption of this emerging market. Hence, this study will look into literature based on new technology and cryptocurrency acceptance and adoption.

\section{Literature Review}

This chapter will explore current literature and provide an overview of theoretical research to evaluate the aim of this study and establish fundamental background knowledge to compose research objectives. The researcher will delve into literature based on the acceptance and adoption of new technologies, more specifically cryptocurrencies.

\subsection{Radical Innovation}

In the modern world, technological changes can be seen as the most powerful component of growth (Sood \& Tellis, 2005). There have been continuous studies (Garud \& Tuertscher, 2013; Adner \& Kapoor, 2016) of the effects, positive and negative, of radical innovation. But these studies have mainly been based within organisations. Radical innovation can create new markets and lead to extraordinary growth (Pham, 2011), which the cryptocurrency market has demonstrated in the short time of its existence. Therefore, it is critical to understand how consumers react and perceive radical innovation so that when changes are proposed they are marketed to suit the consumer, but also that a consumer's intention and motivation is understood.

\subsubsection{Adoption and Attitude 'models'}

Over time there have been various conceptual models for understanding consumer acceptance or adoption of new technology and radical change. Traditionally, models that looked at the acceptance of technology focused on attitudes and usefulness (Masrom, 2007). The Technology Acceptance Model (TAM) was constructed by Davis (1989), which was based on the Theory of Reasoned Action (TRA) (Fishbein \& Ajzen, 1975). TRA was a psychological study to show that an individual's behaviour and intention stemmed from 
HOLISTICA Vol 12, Issue 2, 2021, pp.109-144

the persons beliefs and motivations. TAM model is more specific and proposes how the consumer perceives the ease of use and how useful the technology is establishing a consumer's attitude towards using, the subsequent behavioural intention and the actual use of the new piece of technology. TAM has since been applied to many studies of understanding the behavioural intention for new technology. For example, word processors (Davis et al., 1989), spreadsheet applications (Mathieson, 1991), web browser (Morris \& Dillon, 1997), blackboard (Landry, Griffeth \& Hartman, 2006) and the improvement of financial reporting by utilising blockchain technology (Borhani, 2021).

TPB (Theory of Planned Behaviour) has been applied to the intention of using cryptocurrency, the TPB factors include attitude, subjective norms, and perceived behavioural control as extensions so that non-volitional behaviours are considered for predicting behavioural intention (REF). TPB is a highly respected model and has been applied to e-government research that investigates the adoption of new technologies (Schaupp \& Festa, 2018). TPB explained a 58\% total variance with regards to the intention to use cryptocurrencies (Schaupp, 2018). Which highlights that all the components of the TPB model were found to positively influence the intention to use cryptocurrencies. 'Unified theory of acceptance and use of technology' (UTAUT) (Venkatest et al., 2003) is developed later, taking inspiration from the Theory of Planned Behaviour (Ajzen, 1991). Staying in line with the TAM, the UTAUT explores performance expectancy and effort expectancy with additional factors of social influence and facilitating conditions. The model also adds moderating variables that are assumed to influence the key variables on usage and intention (Omer, 2015), these are focused on: Gender, Age, Experience and Voluntariness of use. These variables show the depth of how demographics can influence a person's attitude towards new technology and their intention to use it (Williams, 2015).

Figure 1 The unified theory of acceptance and use of technology model

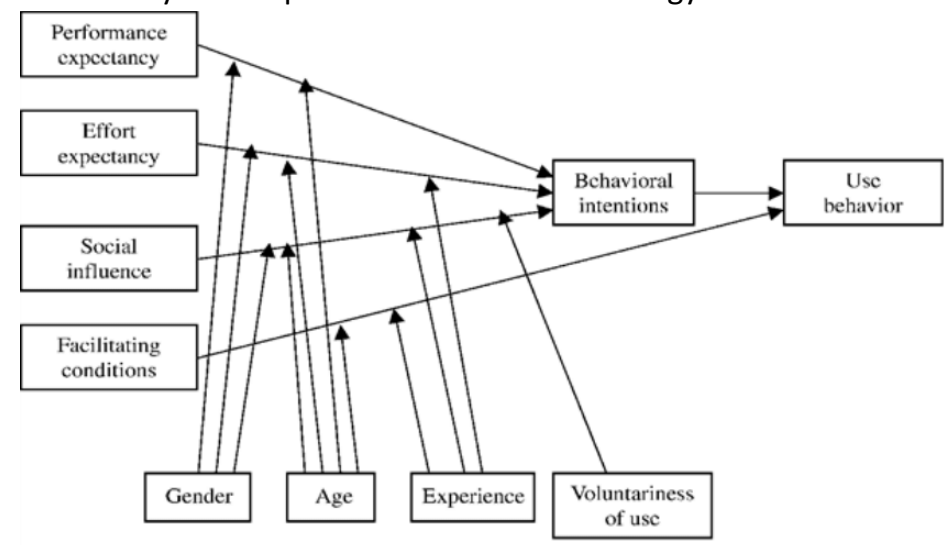

Source: Venkatest, 2003.

Overall, the UTAUT model shows a direct link between the four detrimental factors on the intention to use new technology (Venkatest et al., 2003). The literature surrounding 
UTAUT is not consistent. For example, Moon and Hwang (2018) study found that effort expectancy and social influence positively affected intention to use crowdfunding services. In contrast, performance expectancy and facilitating conditions were important antecedents of a consumer's behavioural intention to use online banking (Khan et al., 2017). When looking at payment authentication systems as an example, it was found that performance and effort expectancy positively affected intention as well as social influence (Kim et al., 2018). Makanyenza and Mutambayashata (2018) looked at the behavioural intention of adopting 'plastic money,' more commonly known as credit or debit cards. They found that performance and effort expectancy were the only variables to positively influence the intention to use 'plastic money'.

When looking at the cryptocurrencies literature, the results were quite contradicting. For example, in one study perceived usefulness was found as the most influential factor in the intention to use cryptocurrencies but there was no direct support that social influence affected the intention to use (Mendoza-Tello et al., 2018). However, in a study based on TPB people who were affected by social influence regarding the use of cryptocurrencies had their intentions to use cryptocurrencies affected positively and negatively, depending on the social influence (Schaupp \& Festa, 2018). Eton and Doige (2018) found that $29 \%$ of Europeans wouldn't invest into cryptocurrencies due to stocks and shares being less risky. Another study by Gao et al. (2016) found that non-users of cryptocurrencies felt incapable of adopting them. Another study found that effort expectancy negatively influenced the intention of use of cryptocurrencies as participants felt cryptocurrencies are a difficult technology to use (Krombholz et al., 2017). However, a study based in China on the acceptance of cryptocurrencies (Shahzad et al., 2018) showed that both perceived usefulness and ease of use significantly influenced the intention to use cryptocurrencies.

\subsubsection{Financial knowledge}

Cryptocurrencies are considered as a financial product. Financial knowledge has been defined as the extent of knowledge a person holds about financial concepts and the capacity in which they can apply their knowledge for financial decision making (Stolper \& Walter, 2017).

There has been a considerable amount of research that illustrates financial knowledge being a predictive factor for financial behaviours (Hastings, 2013; Van Rooij et al., 2011; Lam \& Lam, 2017). Financial literacy is known for being influential in the financial decisionmaking process, this is because people with low levels of financial literacy are considerably less likely to invest in stocks and shares (Van Rooj et al., 2011). This was also demonstrated in Lusardi and Mitchell's (2014) literature review, that the greater the financial knowledge the greater the likeliness is to invest in financial and stock markets. Higher levels of financial knowledge are not always determined by the level of education, whether that is institutional or voluntary, it can be seen as the ability to save money, participate in any regime that can benefit financially, and the selection of financial products, as well as the more tentative an individual is with their everyday spending (Stolper \& Walter, 2017). Research has also shown the direct effect knowledge on individual's participation in 
HOLISTICA Vol 12, Issue 2, 2021, pp.109-144

services such as credit cards, mortgages, investment and retirement savings plan like. The lower the knowledge the less likely a participant is to use those products (Hastings et al., 2013).

\subsection{Social aspects effects on acceptance}

\subsubsection{Gender}

There are studies regarding the difference between genders in technological acceptance, overall, it is seen that males are more confident in their ability to use new technology compared to the female (Vekiri \& Chronaki, 2008). This effects how females accept new technology, which results in women typically exhibiting lower levels of attitude towards technology (Anderson et al., 2008). Some researchers have proposed that the reason for this stigma is that women generally don't currently have many technological role models (Marx \& Roman, 2002), plus, IT occupations are seen as too 'technical,' and 'masculine,' (Kvasny et al., 2011).

Furthermore, as previously stated, cryptocurrency is also seen as an innovative piece of financial technology. Therefore, it is also key to examine the differences in gender when it comes to financial decision making. There has been a variety of research regarding financial decision making between genders and it has found that women are less confident in their abilities to make financial decisions (Zinkhan \& Karande, 1991; Stinerock et al., 1991), while also exhibiting a lower level in risk for the decisions they make (Johnson \& Powell, 1994). Which would produce valid reasoning if it was seen that women felt considerably less comfortable than men to invest in cryptocurrencies because of the highrisk image, however, this research could be seen as outdated as a recent UK survey concluded that 2 in 5 cryptocurrency investors are women (Gemini, 2021).

When looking specifically at gender differences with regards to cryptocurrency, it is easy to see that acceptance could differ due to the amount of exposure. While men still make up of over $50 \%$ of cryptocurrency investors, for women to accumulate as roughly $40 \%$ is astonishing considering nearly 2 out of 3 women feel they are limited to cryptocurrency exposure (Gemini, 2021), this exposure could include all channels of media and general conversation because of the assumption women are less interested in finance or technology (Sieverding \& Koch, 2009; Stinerock et al., 1991). Therefore, must be considered that the reason for men being more open to the investment or intention to use cryptocurrencies is because the exposure they receive and the quality of information through media channels. However, after taking all this into account the author concluded that the research did not need to be gender specific. This was due to the cryptocurrency market being relatively equal and that financial knowledge had already been found to be level between genders. Plus, by it not being gender specific it could produce a greater generalisation of the mass population, which is what the researcher wanted to achieve. Moreover, previous literature highlighted gender differences for technological knowledge and skills, which highlights the influence technological knowledge could have on the perception and intention to use cryptocurrencies. 


\subsubsection{Generational differences}

A generational cohort is constructed of people with comparable life experiences due to the similarity in time periods in which they were raised (Bakewell \& Mitchell, 2003). This has led to presumptions that individuals of a certain cohort tend to have behavioural and psychological traits that coincide with other individuals of that cohort and developing different patterns of values, attitude, and preferences of other cohorts (Parment, 2013).

Looking at literature that focuses on how generational cohorts perceive cryptocurrencies can be conflicting. One study showed that due to the assumption that technological awareness is needed to invest or use cryptocurrencies that the older generations are less likely to use, and because it is an unregulated market, they have less trust (Alaeddin \& Altounjy, 2018). However, Grayscale (2019) found that the average age of investor in the U.S was 45 years old, contradicting that the cryptocurrency market is predominately made up of Generation Z and millennials (18-30 years old), although this could be because of occupational background and the process of mainstream finance firms recognising the opportunity that cryptocurrencies provide (Lammer et al., 2019). Nevertheless, there are conflicting results, this is because nearly $72 \%$ of people aged $45+$ in the UK expressed no interest whatsoever in investing or using cryptocurrencies (Gemini, 2021). While another study highlighted that cryptocurrency adopters tended to be individuals benefiting the least from existing financial systems and opportunities (Johnson \& Krueger, 2021), supporting the idea that the younger generation is more open to the change as they feel it will be more beneficial for themselves in the long run. Plus, it was also seen that Millennials are more likely to adopt cryptocurrencies due to the fact they were raised during the rapid development of technology and that the cryptocurrency market provides a viable way of modernizing capitalism (ING, 2018). The author concluded there was no need to research a specific generational cohort due to previous literature claiming that younger people may invest because of current financial systems not favouring them and older cohorts being investors due to their occupation, therefore, highlighting the potential influence any knowledge has on attitude and intention to use cryptocurrencies.

\subsubsection{Socio-economic and demographic factors}

Many people seem to think that the cryptocurrency market is filled with extremely rich men or young students aiming to get monetary benefits that current financial systems don't provide. Technically, they would be correct. Studies have shown that the average cryptocurrency investor has a significantly higher income compared to those who have not invested in cryptocurrencies (Smyth, 2013) and that, in the UK, 2 out of 5 investors were women (Gemini, 2021). Since men seem to naturally adopt new technology more than women, the market is dominated by the male gender (Lammer et al., 2019).

Due to this, the market is achieving the opposite of what cryptocurrencies originally stood for. Cryptocurrencies were created to be decentralized and unregulated so that it could be a source of income or serve as payment for the unbanked population (Saiedi, 2019). This was to help the unbanked by removing any financial intermediaries that prevented them from purchasing properties as an example (Schaupp, 2018), made possible by 
reducing transaction fees and providing data transparency. Gemini (2021) claimed that the cryptocurrency market wasn't just full of the wealthy population, as $91 \%$ of UK cryptocurrency investors had an income of less that $f 100,000$ a year. This result is quite subjective as the median annual wage in the UK is $f 22,000$ and only $1 \%$ of the UK population earn upwards of $£ 100,000$ (Lambert, 2019).

It is understandable that financial investors are taking advantage of the growth that the cryptocurrency market is providing. But as cryptocurrencies were originally for the unbanked (Saiedi, 2019) this highlights further how the performance of cryptocurrencies impacts people's perception and intention, further highlighting the potential impact financial and technological knowledge can have on an individual's perception and intention.

\subsection{Conclusion}

In a world where cryptocurrencies have become more accessible than ever (Schaupp, 2018) and the process of mass adoption into mainstream markets has begun (Shazad et al., 2018), there are now numerous applications and websites that allow the purchase and transfers of cryptocurrencies, as well as payment merchants like PayPal allowing transactions to be completed using cryptocurrencies and crypto.com becoming a 2021 sponsor for Aston Martin's Formula 1 team. There seems to still be caution when adopting cryptocurrencies as a new technology and the intention to use or invest is relatively low.

Based on the relevant literature, there are four factors that will be explored in this study: The Financial knowledge and its influence on people's intentions to use cryptocurrencies; Technological knowledge is another factor, as previous literature had stated that people felt incapable of using cryptocurrencies and highlighted how different skill sets affected individual's attitude to adopt new technologies. The final two components are performance and effort expectancy. This is because throughout reviewing literature based on the adoption and acceptance of new technologies, including cryptocurrencies. Individuals were highly affected by the ease of use and what the product would provide for them. Taking this all into account the following hypotheses were constructed:

- Hp 1a: There is a positive relationship between Financial Knowledge and attitude towards cryptocurrencies.

- Hp $1 \mathrm{~b}$ : There is a positive relationship between Financial Knowledge and the intention to use cryptocurrencies.

- Hp 2a: There is a positive relationship between Technological Knowledge and attitude towards cryptocurrencies.

- Hp 2b: There is a positive relationship between Technological Knowledge and the intention to use cryptocurrencies.

- Hp 3a: There is a positive relationship between Performance Expectancy and attitude towards cryptocurrencies.

- Hp 3b: There is a positive relationship between Performance Expectancy and the intention to use cryptocurrencies. 
- Hp 4a: There is a positive relationship between Effort Expectancy and attitude towards cryptocurrencies.

- Hp 4b: There is a positive relationship between Effort Expectancy and the intention to use cryptocurrencies.

- Hp 5: Performance and effort expectancy, technological and financial literacy and attitude are all antecedents of intention to use cryptocurrencies.

Figure 2 The researcher's conceptual framework

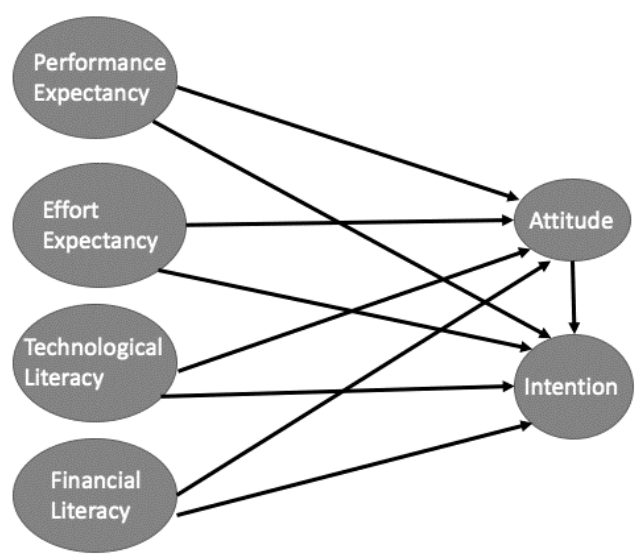

Source: Authors' synthesis, 2021

\section{Methodology}

\subsection{Introduction}

The study follows a positivist perspective that allows the researcher to remain independent from the data with an objective stance (Saunders et al., 2012). A deductive approach is selected, which is usually associated with quantitative methods so that hypotheses can be tested (Robson, 2002) and to stress the importance of selecting a sufficient sample size so that results can be generalised (Saunders et al., 2012).

The method that best suits the research philosophy and approach is a quantitative monomethod, as the best suited tool for this research is a quantitative survey strategy. This is because a deductive approach and a piece of exploratory research is best complemented by a quantitative survey (Saunders et al., 2012). A survey is the most convenient way to gather quantitative results due to the fast and inexpensive nature you can gather data from large samples about attitude's, beliefs, and behaviours (Mitchell \& Jolley, 2013), and with a larger sample it is easier to generalise characteristic results towards a population using statistical methods (Collins \& Hussey, 2014). As there was an absence of an independent investigator, self-administered questionnaires were used for accessible 
HOLISTICA Vol 12, Issue 2, 2021, pp.109-144

distribution and to preserve anonymity, which resulted in a reduction of social desirability (Lin, 2004). Furthermore, by adopting this strategy the participants have greater control due to participating in their own and regular environment. Additionally, to ensure on a high responsiveness from the sample there was some time spent composing and testing the survey (Saunders et al., 2012). To maximise the response rate, participants must trust the researcher (Dilman, 1978) and trust was built by assuring anonymity when responding to the survey.

This study solely focuses on the perception and intention to use cryptocurrencies. Having looked at previous literature, it was deemed unnecessary to research a specific sample regarding age or gender. Therefore, this research was aimed at all adults (18+ years old), as they have the ability and capacity to potentially use or invest in cryptocurrencies. Figure 3 is a demonstration of the gender split in the UK, showing that the population is close to a 50:50 split.

Figure 3 UK gender population split

Source: Statista, 2021

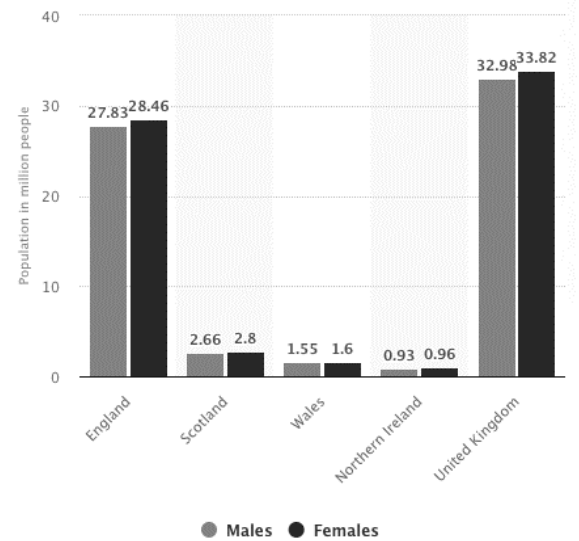

A snowball sampling method was considered as this would give the researcher access to participants that are involved in cryptocurrency networks and forums (Ghauri \& Grønhaug, 2005). However, as the research didn't require participants to be involved in cryptocurrencies already, a convenience sampling was best suited. This is because the sample did not need to be controlled and have certain representatives, plus, it reduces pressure from time constraints (Gravetter \& Forzano, 2012).

As this piece of research has adopted a non-probability sampling method, previous studies have shown that a sample size should be a ratio of 10:1 compared to participants and hypotheses (Hair et al., 2010). Taking this into account, the sample size needs a minimum of 100 participants before the researcher can start identifying relationships in the data to increase statistical power. 
As the surveys are self-administered, the design is vital to ensure that the participants complete the survey themselves (Lee \& Lings, 2008). In previous literature, there have been 3 key components for design methods: adopting existing instruments, adapting and/or modifying existing instruments, and developing new instruments (Tran, 2009). To ensure that results were easy to process statistically and to create increased uniformity, the survey made use of close-ended questions (Babbie, 2010). Additionally, close-ended questionnaires apply speed benefits and will ensure that total time for completion remains relatively low (Maylor \& Blackmon, 2005). The survey applied a balanced 7-point Likert-type scale, as this number would remove the possibility of bundled results while still preserving detailed data (Lee \& Lings, 2008). The structure of the survey was also considered, questions regarding the topic were grouped together and then more personal questions were grouped towards the end (Lee \& Lings, 2008). Furthermore, the number of questions was kept at a minimum as it is known shorter questionnaires generate a higher response rate as it minimises participants frustration (Gill et al., 2010; Brace, 2013).

In the questionnaire design, the study employed existing scales and modified the wording to fit the purpose of the research. To test attitude, the researcher adapted from Chang's (2017), to test technological and financial literacy, scales were adopted from Hasting's (2013) to study the financial literacy and economic outcomes. Plus, consumer intention was adapted from Davis' (1989) Technology Acceptance Model, and performance and effort expectancy were adapted from Venkatesh's (2003) UTAUT model.

The researcher also had to consider order effects, practice and participant fatigue for control measures and to make sure each survey was completed properly (Mitchell \& Jolley, 2010). This was achieved by randomising certain questions regarding intention. Plus, adding in a question stating, 'Please click strongly disagree,' so that the researcher was sure to have each participant's full attention and it allowed the researcher to separate invalid and valid data before analysing further.

\subsection{Pilot survey}

Previous studies have stated that most problems regarding surveys are due to minimal design and planning, as well as, asking the wrong questions (Oppenheimer, 1992). Therefore, to avoid these difficulties a pilot study was employed. Firstly, as the researcher's supervisor is an expert, they provided initial feedback on the survey's suitability. Amendments were made based on the recommendations from the supervisor before the pilot test (Saunders et al., 2012). It's recommended that there are 10 participants involved in the pilot test (Saunders et al., 2012), as this is a sufficient sample to acknowledge any issues with structure, form and understanding (Cargan, 2007). For a structured feedback, a short questionnaire was constructed that applied Bell's (2010) instructions. The pilot survey resulted in an overall satisfaction with the design of the survey, however, some wording was altered to simplify the questions as some participants felt it was confusing. 


\subsection{Questionnaire distribution}

When selecting distribution channels, online distribution was seen as the best fit. This was because it allowed a greater reach than other channels, plus, was seen as most effective due to the low costs and quick completion times (Rose et al., 2015). As previously stated, the sampling method would be a convenience method. As this research didn't require certain demographics or personal interests, making the questionnaire easy to distribute to a broad sample was the main scope. Additionally, $95 \%$ of the UK population own a smart phone (Statista, 2020) so every respondent the questionnaire reached should be capable of completing.

\subsection{Reliability and validity}

With a survey, the reliability and validity are two vital components. For a survey to be reliable, it requires the sample to be able to produce consistent results if completing the survey more than once. Validity is if the survey is collecting data on what is needed (Brace, 2013). From the pilot test, it was apparent that questions were understood, it maintained participants attention and had a logical order. In addition to this, as the survey provided participants with anonymity and there was no interviewer, then social desirability bias would have fallen (Bradburn et al., 2004).

A vast number of researchers have suggested that an optimum points scale, that shouldn't assist in response error, is between 1 and 7 (Krosnic \& Fabigar, 1997) and, therefore, increasing the validity of the data. With non-probability sampling, there can be cases of bias which causes difficulty in generalising the data (Sekaran \& Bougie, 2009). However, non-probability samples can accumulate data that is useful in exploratory research (Wegner, 2007). Additionally, one major problem with self-completion surveys that are online is that it is hard to be certain who is participating in the survey (Bryman \& Bell, 2011). This issue was addressed by the researcher adding an introductory statement that detailed the requirements of the participants needed.

\subsection{Ethical considerations}

Potentially the biggest concerns when conducting research that requires a survey is protecting the sample's interests, well-being, and identity (Babbie, 2010). By using an introductory sheet that defined the data storage systems, who would have access and how long it would be stored for (Oliver, 2010), this dealt with the concerning issues. Moreover, as the survey didn't require personal details, anonymity was established (Saunders et al., 2012). To ensure that participants had provided informed consent based on that they understood the nature of the research, a tick box was provided (Wilson, 2014). Finally, participants were given the option to back out of the survey if at any point they were uncomfortable. An ethics checklist followed, and participants were given an information sheet with a consent form. 


\section{Research findings and analysis}

\subsection{Final sample}

The final sample consisted of 371 people. However, this number was reduced to 126 because of participants not completing the survey fully. Incomplete surveys were a limitation that was accepted when opting for this research method (Zhang, 2000), to combat this, a survey progress bar was provided so that participants knew how far into the survey they were (Denscombe, 2014). Additionally, another 24 responses were invalid and removed from the final sample. The researcher added a question stating to answer with 'Strongly Disagree', to test participant's attention, in which only 102 correctly answered and therefore only their data was valid. Moreover, the sample was relatively evenly split between genders (56:46), but slightly favoured males, which is understandable considering in the UK 3 out of 5 cryptocurrency investors are male (Gemini, 2021). Even though this study didn't require cryptocurrency knowledge because it is a very niche topic this could have potentially caused female participants to not want to take part. As a convenience sampling method was deployed, having a perfect 50:50 split was always going to be difficult. Utilising SPSS, the final sample was screened and there were no errors or missing data (Pallant, 2010).

Table 1 Participant information 1

\begin{tabular}{ccc}
\hline Groups & N & \% \\
\hline Total respondents & 371 & 100 \\
Incomplete survey & 245 & 66.03 \\
Answered attention Q wrong & 24 & 6.5
\end{tabular}

Source: McMorrow, 2021.

Table 2 Participant information 3

Source: McMorrow, 2021.

\begin{tabular}{ccc}
\hline Groups & N & \% \\
\hline Male & 56 & 54.9 \\
Female & 46 & 45.1 \\
Prefer not to say & 0 & 0 \\
\hline
\end{tabular}

Table 3 Participant information 3

\begin{tabular}{ccc}
\hline Groups & N & \% \\
\hline 18-24 Years Old & 56 & 54.9 \\
25-30 Years Old & 11 & 10.8 \\
31-36 Years Old & 17 & 16.7 \\
37-42 Years Old & 3 & 2.9 \\
43-50 Years Old & 6 & 5.9 \\
\hline
\end{tabular}




\section{$50+$ Years old $\quad 9 \quad 8.8$}

Source: McMorrow, 2021.

\subsection{Internal reliability}

Cronbach's Alpha is more commonly known as the reliability coefficient and is widely accepted when estimating the internal consistency of a scale (Garson, 2002), which compares how a group of variables measure against a single unidimensional construct (Andrew et al., 2011). This piece of research used adapted scales from previous studies, therefore, the author felt this research required testing of the reliability of each scale using Cronbach's alpha coefficient (Table 2). When testing reliability, the values of the scale need to be 7 or above (DeVellis, 2003). Table 2 illustrates the internal strength of this piece of research, each value is not lower than .7 and even as high as .940, which highlights that this research has high internal reliability and validates that these results are sufficient for the analysis.

Table 4 Reliability tests

\begin{tabular}{ccc}
\hline Construct & Cronbach's Alpha & N of items \\
\hline Intention & .834 & 3 \\
Performance Expectancy & .940 & 3 \\
Effort Expectancy & .887 & 4 \\
Financial and Technological Knowledge & .768 & 4 \\
Attitude & .916 & 4
\end{tabular}

Source: McMorrow, 2021.

\subsection{Analysis and testing}

When testing hypotheses and ensuring the effectiveness of testing, it is imperative that the best suited statistical analysis tool is selected (Saunders et al., 2012). Therefore, the researcher performed preliminary Kolmogorov-Smirnov and Shapiro-Wilk tests. Appendix 7.2 shows that the preliminary tests resulted in consistent values of $<0.05$, with these figures this means that the results are non-normally distributed and therefore tests that use no distributional assumptions should be utilised (Mooi \& Sarstedt, 2011). Although, this research uses ordinal non-continual data by exercising a Likert scale and therefore non-normal distribution was foreseen (Morgan et al., 2004).

\subsection{Hypotheses}

\subsubsection{Hp $1 a$ and $1 b$}

$\mathrm{Hp} \mathrm{1a:} \mathrm{There} \mathrm{is} \mathrm{a} \mathrm{positive} \mathrm{relationship} \mathrm{between} \mathrm{Financial} \mathrm{Knowledge} \mathrm{and} \mathrm{Attitude} \mathrm{towards}$ cryptocurrencies. 
Figure 4 How financial knowledge affects attitude

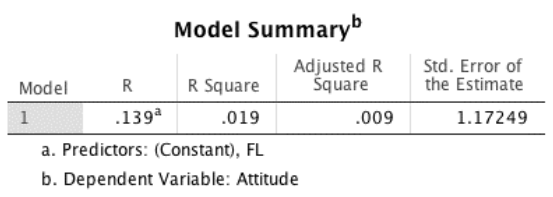

\begin{tabular}{|c|c|c|c|c|c|c|}
\hline \multicolumn{7}{|c|}{ ANOVA $^{a}$} \\
\hline Model & & $\begin{array}{l}\text { Sum of } \\
\text { Squares }\end{array}$ & df & Mean Square & $\mathrm{F}$ & Sig. \\
\hline \multirow[t]{3}{*}{1} & Regression & 2.689 & 1 & 2.689 & 1.956 & $.165^{b}$ \\
\hline & Residual & 137.473 & 100 & 1.375 & & \\
\hline & Total & 140.162 & 101 & & & \\
\hline
\end{tabular}

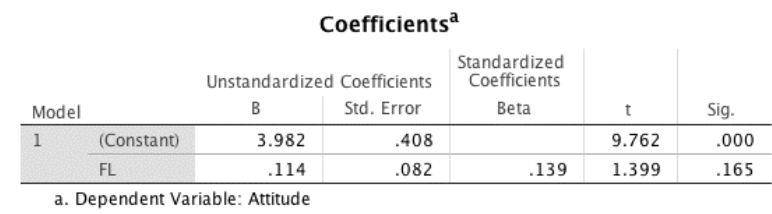

Source: SPSS, 2021.

Figure 4 is the representation of the SPSS results when looking at the effects that financial knowledge has on people's attitude towards cryptocurrencies. To measure this, a simple linear regression test was carried out. The results of the regression indicated that the model exhibited an extremely weak $2 \%$ variance and very low positive correlation $r=.139$. In addition, the model was found to be insignificant, $F(1,100)=1.956, p>.005$. Therefore, taking all the statistics into consideration the researcher found that the data did not support the hypothesis.

$\mathrm{Hp} 1 \mathrm{~b}$ : There is a positive relationship between Financial Knowledge and the intention to use cryptocurrencies. 
HOLISTICA Vol 12, Issue 2, 2021, pp.109-144

Figure 5 How financial knowledge affects intention

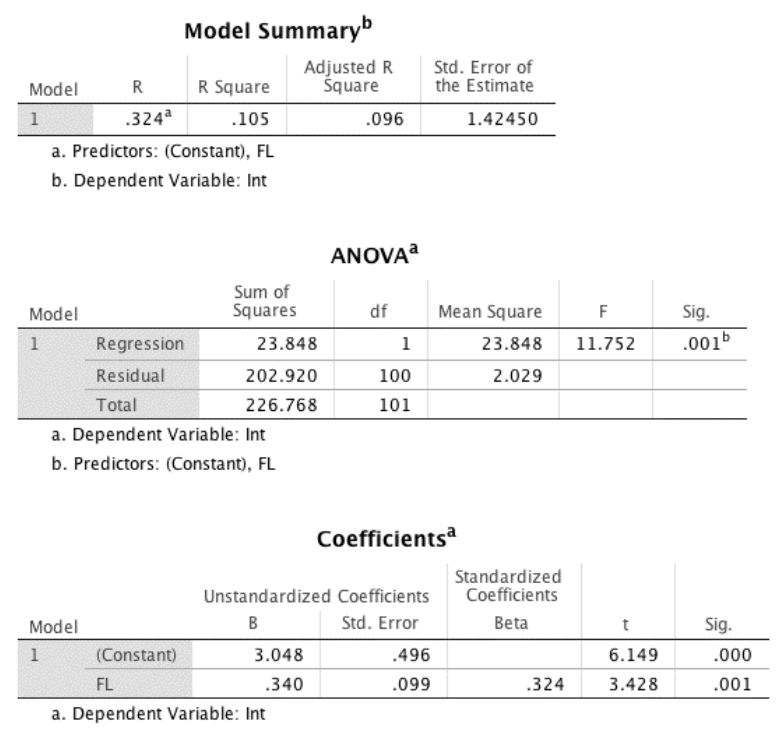

Source: SPSS, 2021.

Figure 5 shows the SPSS results for how financial knowledge affects people's intentions to use cryptocurrencies in any capacity, whether their intention is purposely for trading or as form as transactions. Using a simple linear regression test, the results again indicated a very weak variance of $10.5 \%$. Although, this variance from financial knowledge was stronger on intention rather than attitude and this was also highlighted with a slightly stronger positive correlation of $r=.324$. However, this model for intention was found to be significant as $F(1,100)=11.752, p<.005$. results support the hypothesis. While the variance and positive correlation remain very weak, they still provide data showing explanatory power (Wasserman, 2007), plus, this model was found to be significant.

\subsubsection{Hp $2 a$ and $2 b$}

Hp 2a: There is a positive relationship between Technological Knowledge and attitude towards cryptocurrencies. 
Figure 6 How technological knowledge affects attitude

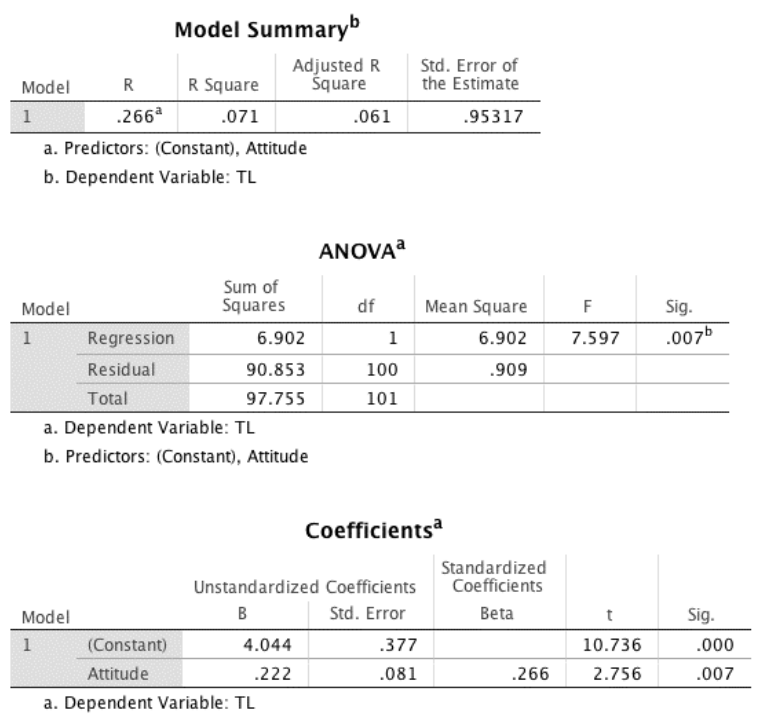

Source: SPSS, 2021.

Figure 6 exhibits the SPSS results for how technological knowledge affects people's attitude towards cryptocurrencies. Once again this was tested using linear regression. Just like the model for financial knowledge and attitude this showed an extremely weak variance, although technological knowledge had a slightly stronger variance of $7 \%$ and the positive correlation was found to be stronger at $r=.266$. Additionally, this model for attitude towards cryptocurrencies was found to be significant as $F(1,100)=7.596, p<.005$, unlike the model for attitude from financial knowledge. The results concluded that these values did support the validation of hypothesis 2 . While again the values were still very weak, they still exhibited a positive correlation between the independent and dependant variable exhibiting that there was some explanatory power (Sirkin, 2006) and the model is also significant.

$\mathrm{Hp} \mathrm{2b:} \mathrm{There} \mathrm{is} \mathrm{a} \mathrm{positive} \mathrm{relationship} \mathrm{between} \mathrm{Technological} \mathrm{Knowledge} \mathrm{and} \mathrm{the}$ intention to use cryptocurrencies. 
HOLISTICA Vol 12, Issue 2, 2021, pp.109-144

Figure 7 How technological knowledge affects intention

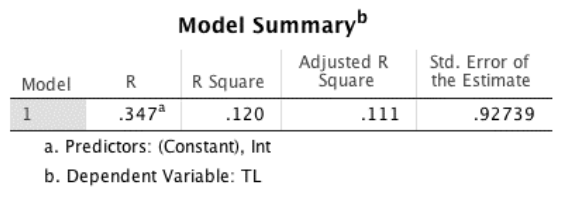

\begin{tabular}{|c|c|c|c|c|c|c|}
\hline \multicolumn{7}{|c|}{ ANOVA $^{\mathrm{a}}$} \\
\hline Model & & $\begin{array}{l}\text { Sum of } \\
\text { Squares }\end{array}$ & df & Mean Square & $\mathrm{F}$ & Sig. \\
\hline \multirow[t]{3}{*}{1} & Regression & 11.749 & 1 & 11.749 & 13.661 & $.000^{\mathrm{b}}$ \\
\hline & Residual & 86.006 & 100 & .860 & & \\
\hline & Total & 97.755 & 101 & & & \\
\hline
\end{tabular}

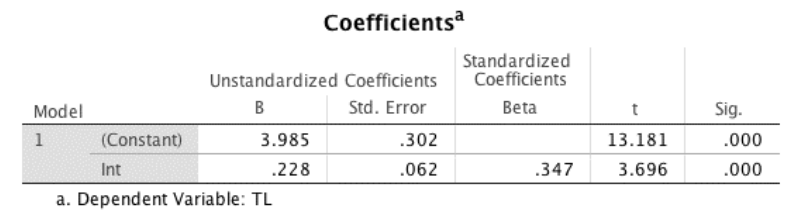

Source: SPSS, 2021.

Figure 7 illustrates the SPSS results for how technological knowledge affects people's intentions to use or invest in cryptocurrencies. As before, this was tested using a linear regression model. The variance for intention was greater than attitude, with a small increase to $12 \%$, however, this is still a very weak variance, and the positive correlation was slightly stronger at $r=.347$. Furthermore, this model for intention to use cryptocurrencies was found to be significant as $F(1,100)=13.661, p<.005$. After examining each value between the independent and dependent variables, this model supported $\mathrm{Hp2}$. Although the positive correlation remains very weak, it is still clear that the greater the technological knowledge the more positive attitude towards cryptocurrencies and the greater intent to use cryptocurrencies further highlighting that technological knowledge does provide some explanatory power (Wasserman, 2007). This was the first hypothesis to be fully supported by the data produced from the survey.

\subsubsection{Hp $3 a$ and $3 b$}

$\mathrm{Hp} \mathrm{3a:} \mathrm{There} \mathrm{is} \mathrm{a} \mathrm{positive} \mathrm{relationship} \mathrm{between} \mathrm{Performance} \mathrm{Expectancy} \mathrm{and} \mathrm{attitude}$ towards cryptocurrencies. 
Figure 8 How performance expectancy affects attitude

\begin{tabular}{|c|c|c|c|c|}
\hline \multicolumn{5}{|c|}{ Model Summary } \\
\hline Model & $\mathrm{R}$ & R Square & $\begin{array}{l}\text { Adjusted R } \\
\text { Square }\end{array}$ & $\begin{array}{l}\text { Std. Error of } \\
\text { the Estimate }\end{array}$ \\
\hline 1 & $.779^{\mathrm{a}}$ & .606 & .602 & .88896 \\
\hline
\end{tabular}

\begin{tabular}{|c|c|c|c|c|c|c|}
\hline \multicolumn{7}{|c|}{ ANOVA $^{\mathrm{a}}$} \\
\hline \multicolumn{2}{|l|}{ Model } & $\begin{array}{l}\text { Sum of } \\
\text { Squares }\end{array}$ & df & Mean Square & $\mathrm{F}$ & Sig. \\
\hline \multirow[t]{3}{*}{1} & Regression & 121.678 & 1 & 121.678 & 153.974 & $.000^{\mathrm{b}}$ \\
\hline & Residual & 79.025 & 100 & .790 & & \\
\hline & Total & 200.703 & 101 & & & \\
\hline \multicolumn{7}{|c|}{ a. Dependent Variable: PE } \\
\hline \multicolumn{7}{|c|}{ b. Predictors: (Constant), Attitude } \\
\hline \multicolumn{7}{|c|}{ Coefficients $^{a}$} \\
\hline \multicolumn{7}{|c|}{ Unstandardized Coefficients } \\
\hline \multicolumn{2}{|l|}{ Model } & B & Std. Error & Beta & $\mathrm{t}$ & Sig. \\
\hline \multirow[t]{2}{*}{1} & (Constant) & -.112 & .351 & & -.320 & .750 \\
\hline & Attitude & .932 & .075 & .779 & 12.409 & .000 \\
\hline
\end{tabular}

Source: SPSS, 2021.

Figure 8 depicts the SPSS results for how performance expectancy affects people's attitudes towards cryptocurrencies. This was tested using a linear regression model and was found to be the researchers most effective variable. The variance caused by performance expectancy on attitude was a moderate $60 \%$ and the positive correlation was $r=.779$, meaning this model produced the strongest correlation. Additionally, this model for people's attitude towards cryptocurrencies was found to be significant as $F(1,100)=153.974, p<.005$. Having established a positive correlation between performance expectancy and people's attitude towards cryptocurrencies, these results supported the hypothesis and recognised that performance expectancy was the most influential variable on people's attitudes towards cryptocurrencies.

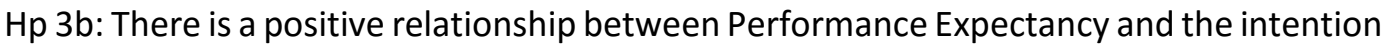
to use cryptocurrencies. 
HOLISTICA Vol 12, Issue 2, 2021, pp.109-144

Figure 9 How performance expectancy affects intention

\begin{tabular}{|c|c|c|c|c|}
\hline \multicolumn{5}{|c|}{ Model Summary } \\
\hline Model & $\mathrm{R}$ & $R$ Square & $\begin{array}{l}\text { Adjusted R } \\
\text { Square }\end{array}$ & $\begin{array}{l}\text { Std. Error of } \\
\text { the Estimate }\end{array}$ \\
\hline 1 & $.631^{\mathrm{a}}$ & .398 & .392 & 1.09936 \\
\hline
\end{tabular}

\begin{tabular}{|c|c|c|c|c|c|c|}
\hline \multicolumn{7}{|c|}{ ANOVA $^{a}$} \\
\hline Model & & $\begin{array}{l}\text { Sum of } \\
\text { Squares }\end{array}$ & df & Mean Square & $\mathrm{F}$ & Sig. \\
\hline \multirow[t]{3}{*}{1} & Regression & 79.844 & 1 & 79.844 & 66.064 & $.000^{\mathrm{b}}$ \\
\hline & Residual & 120.859 & 100 & 1.209 & & \\
\hline & Total & 200.703 & 101 & & & \\
\hline
\end{tabular}

\begin{tabular}{|c|c|c|c|c|c|c|}
\hline \multicolumn{7}{|c|}{ Coefficients $^{\mathrm{a}}$} \\
\hline & & \multicolumn{2}{|c|}{ Unstandardized Coefficients } & \multirow{2}{*}{$\begin{array}{c}\text { Standardized } \\
\text { Coefficients } \\
\text { Beta }\end{array}$} & \multirow[b]{2}{*}{$t$} & \multirow[b]{2}{*}{ Sig. } \\
\hline Model & & B & Std. Error & & & \\
\hline \multirow[t]{2}{*}{1} & (Constant) & 1.333 & .358 & & 3.720 & .000 \\
\hline & Int & .593 & .073 & .631 & 8.128 & .000 \\
\hline
\end{tabular}

Source: SPSS, 2021.

Figure 9 is the representation of the SPSS results for how performance expectancy affects people's intention to use or invest in cryptocurrencies. As before, this was tested using a linear regression model. The variance on intention to use cryptocurrencies created because of performance expectancy was $40 \%$, which is still weak but one of the strongest variance's so far and replicated that with a positive correlation of $r=.631$. Moreover, this test found the model to be significant as $F(1,100)=66.064, p<.005$. It was evident that there was a positive correlation between performance expectancy and people's intention to use cryptocurrencies and, as the model was proved to be significant, the results support the hypothesis. This means that this hypothesis was fully supported. Notably, performance expectancy was the only variable to create greater variance on attitude, rather than intention.

\subsubsection{Hp $4 a$ and $4 b$}

Hp 4a: There is a positive relationship between Effort Expectancy and attitude towards cryptocurrencies. 
Figure 10 How effort expectancy affects attitude
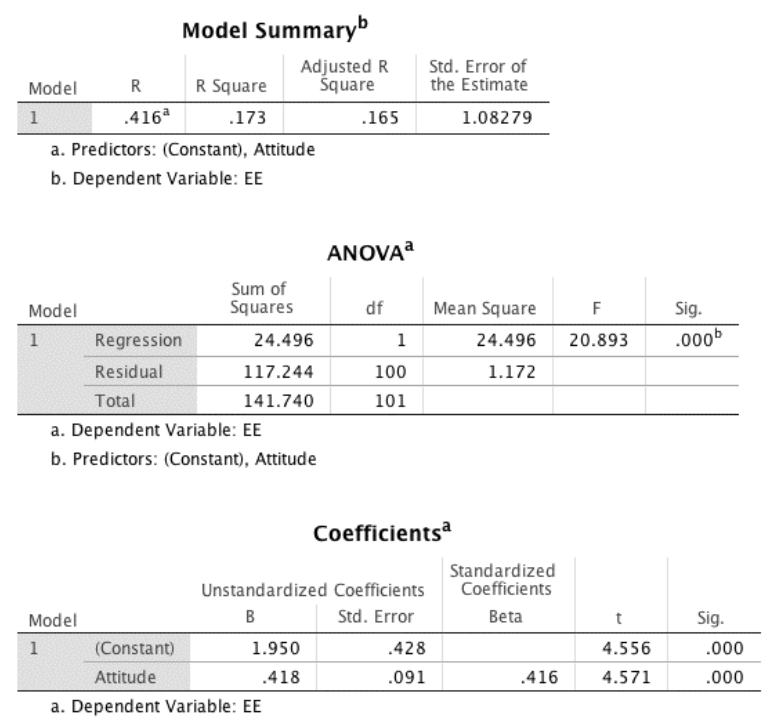

Source: SPSS, 2021.

Figure 10 shows the SPSS results for how effort expectancy affects people's attitude towards cryptocurrencies. This was tested using a linear regression model. In this model, the variance caused by effort expectancy on people's attitude towards cryptocurrencies was weak, at $17 \%$, and this was also seen in the positive correlation only being $r=.416$. While both values showed there was a weak relationship between the two variables, it was still clear that there was a positive correlation between them and showing further explanatory power (Sirkin, 2006). In addition to this, the model was found to be significant as $F(1,100)=20.893, p<.005$. Taking all the results into consideration, the hypothesis was validated.

$\mathrm{Hp}$ 4b: There is a positive relationship between Effort Expectancy and the intention to use cryptocurrencies. 
HOLISTICA Vol 12, Issue 2, 2021, pp.109-144

Figure 11 How effort expectancy affects intention
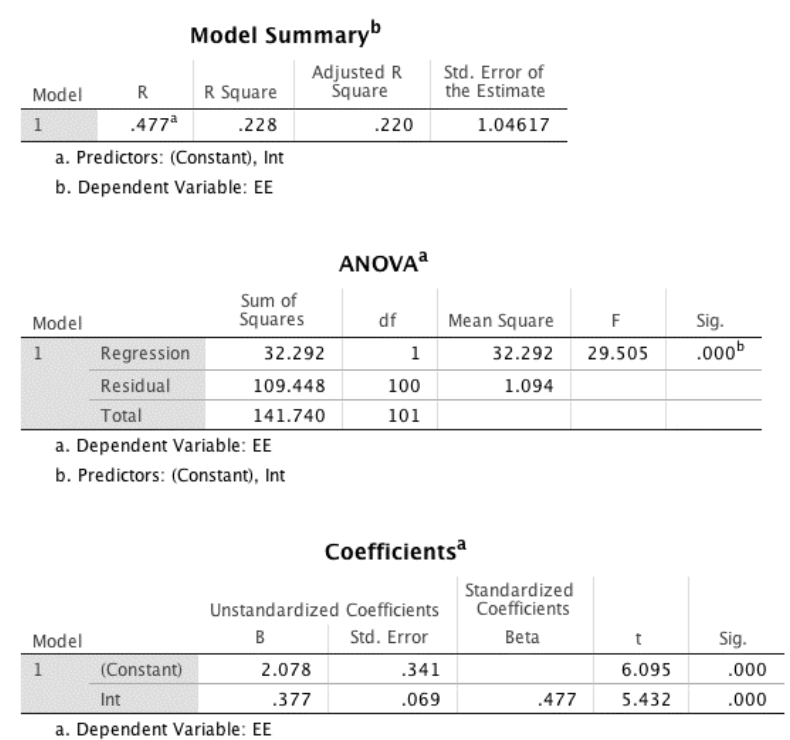

Source: SPSS, 2021.

Figure 11 illustrates the SPSS results for how effort expectancy affects people's intention to use or invest in cryptocurrencies. Replicating previous tests, this test utilised a linear regression model. This model showed that the variance caused by effort expectancy on people's intention to use or invest in cryptocurrencies was $23 \%$, which is relatively weak, and this was supported with a positive correlation of only $r=.477$. Although these figures are deemed as weak, it is still evident that there is a positive correlation between effort expectancy and people's intention to use cryptocurrencies showing that there is some explanatory power (Wasserman, 2007). Plus, this model was found to be significant as $F(1,100)=29.505, p<.005$ which supported the hypothesis.

\subsubsection{Hp 5}

Hp5: Attitude is an antecedent of intention to use cryptocurrencies. 
Figure 12 How attitude affects intention

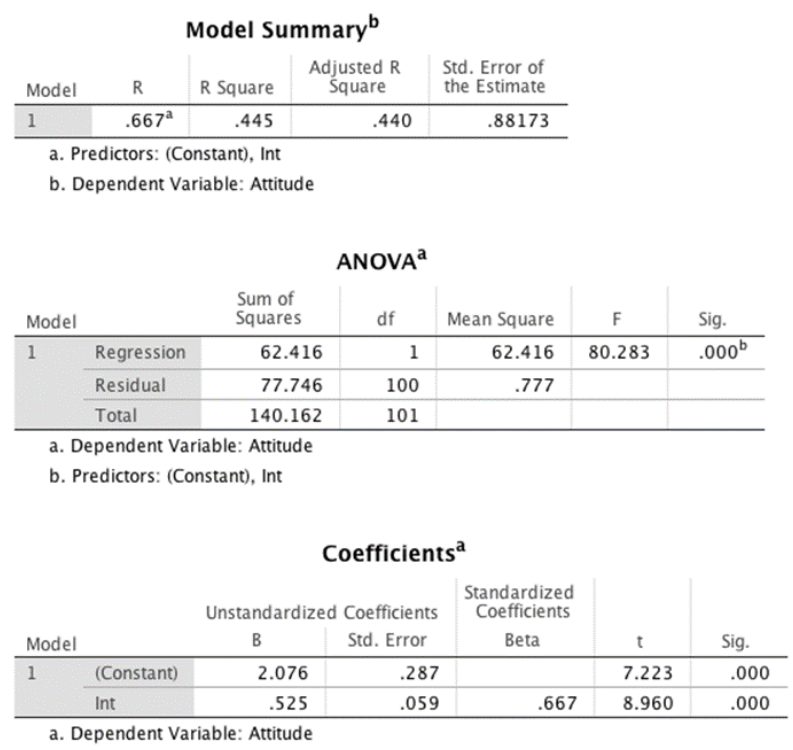

Source: SPSS, 2021.

Figure 12 exhibits the SPSS results for how attitude affects people's intention to use cryptocurrencies. Mimicking previous tests, the researcher used a linear regression model. From this model, the variance was found to be $45 \%$, the second highest of any variance in testing and close to a moderate level. The positive correlation was $r=.667$ and this model was found to be significant as $F(1,100)=80.283, p<.005$. Therefore, taking in the results from every test, the values support the hypothesis that every independent variable tested and attitude are antecedents of intention to use cryptocurrencies.

Table 5 Hypotheses summary

\begin{tabular}{cccc}
\hline Hypothesis & Test & Sig. (p) & Conclusion \\
\hline Hp 1a & Linear Regression & $\mathrm{p}>.05$ & Hypothesis Rejected \\
Hp 1b & Linear Regression & $\mathrm{p}<.05$ & Hypothesis Supported \\
Hp 2a & Linear Regression & $\mathrm{p}<.05$ & Hypothesis Supported \\
Hp 2b & Linear Regression & $\mathrm{p}<.05$ & Hypothesis Supported \\
Hp 3a & Linear Regression & $\mathrm{p}<.05$ & Hypothesis Supported \\
Hp 3b & Linear Regression & $\mathrm{p}<.05$ & Hypothesis Supported \\
Hp 4a & Linear Regression & $\mathrm{p}<.05$ & Hypothesis Supported \\
Hp 4b & Linear Regression & $\mathrm{p}<.05$ & Hypothesis Supported \\
Hp 5 & Linear Regression & $\mathrm{p}<.05$ & Hypothesis Supported
\end{tabular}

Source: McMorrow, 2021. 
This research was conducted so that a better understanding of people's perception and intention to use new financial technology, specifically cryptocurrencies could be made. The conceptual framework (Figure 5) was based on variables that were exhibited in the UTAUT technology acceptance model (Figure 4) (Venkatest et al., 2003). Financial and technological knowledge were also added as variables for specific analysis of cryptocurrency acceptance (Arias-Olia, 2019). The proposed model explains a total $85.5 \%$ variance on the intention to use cryptocurrencies and a variance of $86 \%$ on the attitude towards cryptocurrencies. This final section will summarise the key findings, any implications, the limitations that the researcher found and suggest areas to research further.

\subsection{Summary}

\subsubsection{Financial knowledge}

Quite a significant finding was how weak the positive correlation between financial knowledge, attitude and intention was in this piece of research. Firstly, the test between financial knowledge and attitude was found to be insignificant, which was the only insignificant model that was part of this research. As all previous literature (Hastings, 2013; Lusardi \& Mitchell, 2014) was focused on the influence financial knowledge had on financial decision making, rather than the financial aspect of cryptocurrencies, the researcher expected to make a discovery of the link between financial knowledge and people's attitude and intention towards cryptocurrencies. While the correlation is very weak, it is undeniable that there is still a correlation meaning that this research supports previous literature of financial knowledge positively influences people's intention to use cryptocurrencies (Arias-Oliva, 2019). Notably, the variance created on intention was greater than attitude.

\subsubsection{Technological Knowledge}

As cryptocurrencies are an emerging technology this is an important factor to consider when making assumptions on people's intention and attitude towards cryptocurrencies. While technological knowledge had a stronger correlation and variance compared to financial knowledge, both were still weak. Therefore, these results could support previous literature that people felt incapable of using cryptocurrencies (Gao et al., 2016) and that while people might feel capable of using new technology like smart phones or apps that cryptocurrencies is a technology that is outside of their skill set (Krombholz et al., 2017). However, the correlation still supports previous literature stating that people were more positive towards new technologies if they had a greater technological background (Gao et al., 2016; Schaupp \& Festa, 2018). Once again, the variance technological knowledge caused was greater for intention than attitude.

\subsubsection{Performance expectancy}

When looking at people's attitude and intention to use new technologies, performance expectancy was one of the most prominent factors (Moon \& Hwang, 2018; Kim et al., 2018; Khan et al., 2017) and with regards to literature more specific to cryptocurrencies 
performance expectancy was seen as the most influential factor (Mendoza-Tello et al., 2018; Farah et al., 2018). In this research performance expectancy was found to be the most influential independent variable on people's attitude and intention to use cryptocurrencies, which is consistent with previous literature (Mendoza-Tello et al., 2018; Shahzad et al., 2018). The models testing performance expectancy's correlation to attitude and intention was the only test that resulted in a greater variance for attitude instead of intention. Highlighting that the potential monetary benefits cryptocurrencies could offer or the thought of reaching personal goals quicker impacted people's perception more than just knowledge of what cryptocurrencies can provide.

\subsubsection{Effort expectancy}

Effort expectancy has been found in multiple pieces of literature relating to the adoption of new technologies (Makanyenza \& Mutambayashta, 2018; Moon \& Hwang, 2018), and more specifically cryptocurrencies (Gao et al., 2016; Schaupp \& Fest, 2018). In previous literature effort expectancy has also been labelled as the ease of use or perceived behavioural control. Effort expectancy has been very influential when researching the adoption of new technology, this is because if a person feels incapable of using it, then they wouldn't adopt that technology. In this research, just like other variables, effort expectancy caused a weak variance on attitude and intention but the positive correlation between variables was still visible. Furthermore, the data gathered from this research would support previous literature that effort expectancy does positively influence the intention to use cryptocurrencies (Shahzad et al., 2018; Schaupp, 2018). However, effort expectancy was not found to be the most influential and not as critical to the success of cryptocurrency adoption when compared to performance expectancy.

\section{Discussions and Conclusions}

\subsection{Contributions}

This research has made several theoretical contributions to the perception and intention on using cryptocurrencies, whilst highlighting contradictions from previous literature and should be considered for further research. This study dived into a more personal level of what people think of cryptocurrencies and their acceptance of the new technology, which had yet to be realised due to the market still very much being in the infancy stage. There were positive results showing the strength of which independent variables affect people's attitude and intention, while also highlighting that some theoretical predictions were not as influential as it was first thought. This research also created a framework for attitude and intention that can be adapted in related future research.

\subsection{Implications}

The cryptocurrency market has undergone rapid expansion, and this has led to a significant increase in the number of investors and users of the emerging technology, even some companies are using it as a form of liquidation of assets. The research's findings and framework (Figure 5) identified can be used to guide cryptocurrency developers on how 
to develop and market their virtual currency to the mass population by addressing what people expect and demand from a cryptocurrency. For example, some may invest and hold to increase their wealth, therefore, developing a cryptocurrency that has the potential for an inflation of price will need a well worked project plan. Others may use cryptocurrencies to speed up transactions and have a more transparent monetary system, so cryptocurrency developers should promote the speed of transactions. Cryptocurrency innovators must market to ensure that potential investors or customers perceive the value. In addition, this research has investigated the background knowledge of a person financially and technologically and highlighted which background may be more influential in the market.

\subsection{Limitations and recommendations for further research}

Mainly due to time constraints and the sourcing capabilities of the researcher, it was difficult to gather a sample that could represent the entire population with high confidence (Gill et al., 2010). This was likely to affect the generalisability of data, but despite this, valid assumptions were still made about the sample. Additionally, due to the sampling method used being non-probability, it meant that a vast majority of participants were students at Bournemouth University. Although the convenience method would have reached respondents from different areas in the UK. Future research should provide a greater timeframe to facilitate respondents by utilising a probability sampling method so that a broader knowledge of cryptocurrency acceptance in society can be gained. Possibly by looking into a greater geographical area, as it is very likely that participants from different countries will have a different output on cryptocurrencies. Moreover, allowing the research to offer some sort of compensation or incentive so that the response rate can be more significant, to produce a larger sample and to accommodate for the lack of attention some respondents showed in this survey (Johnston et al., 2014).

Another factor that was not tested in this research was the sustainability of cryptocurrencies, especially as the modern world demands more sustainable consumption and development, this could be an influential factor. This is because the mining process of cryptocurrencies requires immense computation resources that can withhold large energy consumption. In comparison with how much energy is required for 1 US\$ of Bitcoin, is 12 megajoules more than if you were to obtain 1 US\$ of gold (Krause \& Tolaymat, 2018). Therefore, the sustainability of cryptocurrencies should be factored in when researching people's perception and intention as it could be an influential factor throughout.

The researcher opted for a quantitative mono-method. This was due to the lack of previous research on the perception and intention of cryptocurrencies. Therefore, the researcher believed this method was best suited due to time constraints and to construct more reliable generalisations of the population (Hyde, 2000). However, after careful thought the researcher believes with lengthier time constraints and greater skill, as well as a mixed method would be better suited. This is because while a generalisation is still able to be concluded it gives greater insight into why individuals think a certain way about 
cryptocurrencies and what they possibly aim to achieve from the emerging technology (Wilson, 2014).

\section{References}

Adner, R., \& Kapoor, R. (2015). Innovation ecosystems and the pace of substitution: Re-examining technology S-curves. Strategic Management Journal, 37(4): 625-648. https://doi.org/10.1002/smj.2363.

Ajzen, I. (1991). The theory of planned behavior. Organizational Behavior And Human Decision Processes, 50(2): 179-211. https://doi.org/10.1016/0749-5978(91)90020-t

Alaeddin, O., \& Altounjy, R. (2021). Trust, Technology Awareness and Satisfaction Effect into the Intention to Use Cryptocurrency among Generation Z in Malaysia. Universiti Kuala Lumpur Business School, Malaysia.

Anderson, N., Lankshear, C., Timms, C., \& Courtney, L. (2008). 'Because it's boring, irrelevant and I don't like computers': Why high school girls avoid professionally-oriented ICT subjects. $\begin{array}{llll}\text { Computers \& Education, 1304-1318. } & \text { 50(4): }\end{array}$ https://doi.org/10.1016/j.compedu.2006.12.003.

Andrew, D., Pedersen, P., \& McEvoy, C. (2011). Research Methods and Design in Sport Management. https://doi.org/10.5040/9781492596417.

An Introduction to Smart Contracts and Their Potential and Inherent Limitations. The Harvard Law School Forum on Corporate Governance. (2021). Accessed July 7, 2021. https://corpgov.law.harvard.edu/2018/05/26/an-introduction-to-smart-contracts-andtheir-potential-and-inherent-limitations.

Assael, H. (1998). Consumer behavior and marketing action (6th ed.). South-Western Publishing Co.

Bailey, D.K. (1994). Methods of Social Research (4th ed.). Macmillan.

Bakewell, C., \& Mitchell, V. (2003). Generation Y female consumer decision-making styles. International Journal of Retail \& Distribution Management, 31(2): 95-106. https://doi.org/10.1108/09590550310461994.

Bambrough, B. (2020). Why America's Biggest Bank Is Suddenly Very Bullish On Bitcoin. Forbes. Accessed July 6, 2021. https://www.forbes.com/sites/billybambrough/2020/10/26/whyamericas-biggest-bank-is-suddenly-very-bullish-on-bitcoin/.

Bell. (2010). Doing your Research Project (5th ed.). Open University Press.

Bell, E., Bryman, A., Harley, B., \& Bryman, A. (2011). Business research methods (3rd ed.). Oxford University Press.

Bitcoin (BTC) news \& cryptocurrency news today, price \& analysis. NewsBTC. (2020). Accessed July 7, 2021. https://www.newsbtc.com/interview/john-mcafee-interview-bitcoin-willbecome-the-gold-standard/>.

Blaikie, N., \& Priest, J. (2010). Designing social research (2nd ed.). Polity.

Borhani, S., Babajani, J., Raeesi Vanani, I., Sheri Anaqiz, S., \& Jamaliyanpour, M. (2021). Adopting Blockchain Technology to Improve Financial Reporting by Using the Technology Acceptance Model (TAM). International Journal Of Finance \& Managerial Accounting, 6(22): 155-171.

Brace, I. (2013). Questionnaire design: how to plan, structure, and write survey material for effective market research. Choice Reviews Online, 51(02): 51-0965-51-0965. https://doi.org/10.5860/choice.51-0965.

Bradburn, N., Sudman, S., \& Wansink, B. (2004). Asking questions. Jossey-Bass.

Carson, B., Romanelli, G., Walsh, P., \& Zhumaev, A. (2018). Blockchain beyond the hype: What is the strategic business value? Mckinsey Digital. Accessed July 7, 2021. 
https://www.mckinsey.com/business-functions/digital-mckinsey/our-insights/blockchainbeyond-the-hype-what-is-the-strategic-business-value.

Cargan, L. (2007). Doing social research. Rowman \& Littlefield Publishers.

Chang, C. (2017). A Metacognitive Model of the Effects of Susceptibility to Persuasion Self-Beliefs on Advertising Effects. Journal Of Advertising, 46(4): 487-502. https://doi.org/10.1080/00913367.2017.1392911.

CoinGecko: Cryptocurrency Prices and Market Capitalization. CoinGecko. (2021). Accessed July 7, 2021. https://www.coingecko.com/en.

Collis, J., \& Hussey, R. (2014). Business Research: A Practical Guide for Undergraduate and Postgraduate Students (4th ed.). Palgrave Macmillan.

Crotty, M. (2018). The Foundations of Social Research. Sage.

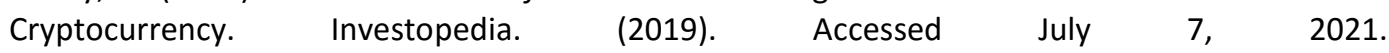
https://www.investopedia.com/terms/c/cryptocurrency.asp.

Cryptocurrencies \& Bitcoin History: How it all Began | Ledger. Ledger. (2019). Accessed July 7, 2021. https://www.ledger.com/academy/crypto/a-brief-history-on-bitcoincryptocurrencies\#: :text=Ten\%20years\%20ago\%2C\%20Bitcoin\%20emerged\%20as\%20the \%20first\%20cryptocurrency.

Davis, F. (1989). Perceived Usefulness, Perceived Ease of Use, and User Acceptance of Information Technology. MIS Quarterly, 13(3): 319. https://doi.org/10.2307/249008

Deloitte. (2015). State-Sponsored Cryptocurrency: Adapting the best of Bitcoin's Innovation to the $\begin{array}{llll}\text { Payments } \quad \text { Ecosystem. } & \text { Accessed }\end{array}$ https://www2.deloitte.com/content/dam/Deloitte/au/Documents/financialservices/deloitte-au-fs-state-sponsored-cryptocurrency-180516.pdf.

Denscombe, M. (2014). The Good Research Guide: For Small-Scale Social Research Projects (5th ed.). McGraw-Hill.

DeVellis, R. (2003). Scale development (2nd ed.). Sage Publications.

Dillman, D. (1978). Mail and telephone surveys. John Wiley \& Sons.

Dobson, P. (2001). The Philosophy of Critical Realism-An Opportunity for Information Systems $\begin{array}{llll}\text { Research. Information Systems } & \text { 199-210. }\end{array}$ https://doi.org/10.1023/a:1011495424958.

Faqih, K. (2016). An empirical analysis of factors predicting the behavioral intention to adopt Internet shopping technology among non-shoppers in a developing country context: Does gender matter? Journal of Retailing And Consumer Services, 30: 140-164. https://doi.org/10.1016/j.jretconser.2016.01.016.

Farah, M., Hasni, M., \& Abbas, A. (2018). Mobile-banking adoption: empirical evidence from the banking sector in Pakistan. International Journal Of Bank Marketing, 36(7): 1386-1413. https://doi.org/10.1108/ijbm-10-2017-0215.

Featherman, M., \& Pavlou, P. (2003). Predicting e-services adoption: a perceived risk facets perspective. International Journal Of Human-Computer Studies, 59(4): 451-474. https://doi.org/10.1016/s1071-5819(03)00111-3.

Fishbein, M., \& Ajzen, I. (1980). Belief, attitude, intention, and behavior. Addison-Wesley.

Gao, X., Clark, G., \& Lindqvist, J. (2016). Of Two Minds, Multiple Addresses, and One Ledger. Proceedings Of The $2016 \mathrm{CHI}$ Conference On Human Factors In Computing Systems. https://doi.org/10.1145/2858036.2858049.

Garson, G. (2002). Guide to Writing Empirical Papers, Theses, and Dissertations. Marcel Dekker. 
HOLISTICA Vol 12, Issue 2, 2021, pp.109-144

Garud, R., Tuertscher, P., \& Van de Ven, A. (2013). Perspectives on Innovation Processes. The $\begin{array}{llll}\text { Academy Of Management } & \text { 7(1): }\end{array}$ https://doi.org/10.1080/19416520.2013.791066.

Ghauri, P., \& Grønhaug, K. (2005). Research methods in business studies (3rd ed.). Financial Times Prentice Hall.

Gill, J., Johnson, P., \& Clark, M. (2010). Research methods for managers. Sage.

$\mathrm{GmbH}$, f. (2021). Bitcoin's market cap could hit $\$ 1$ trillion in 2021 as its growing reserve currency status drives adoption higher, a cryptocurrency expert says. markets.businessinsider.com. Accessed July 7, 2021. https://markets.businessinsider.com/currencies/news/bitcoinmarket-cap-could-hit-1-trillion-2021-crypto-expert-2020-12-1029908224.

Gravetter, F., \& Forzano, L. (2012). Research Methods for the Behavioral Sciences (5th ed.). Cengage Learning.

Grayscale. (2019). Bitcoin Investor Report. Accessed July 7, 2021. https://dropgold.com/bitcoininvestor-report-

timeline/?utm_medium=pr\&utm_source=release\&utm_campaign=2019_q3_BTC_in_sur.

Hair, J. (2010). Multivariate Data Analysis: A Global Perspective (7th ed.). Pearson.

Hassard, J., \& Pym, D. (1990). The Theory and Philosophy of Organizations: Critical Issues and New Perspectives. Routledge.

Hastings, J., Madrian, B., \& Skimmyhorn, W. (2013). Financial Literacy, Financial Education, and Economic Outcomes. Annual Review Of Economics, 5(1): 347-373. https://doi.org/10.1146/annurev-economics-082312-125807.

Helms, K. (2020). Spain Approves Bill Requiring Cryptocurrency Owners to Disclose Crypto Holdings - Regulation Bitcoin News. Bitcoin News. Accessed July 6, 2021. https://news.bitcoin.com/spain-cryptocurrency-disclose-crypto-holdings-gains/.

Hileman, G., \& Rauchs, M. (2017). 2017 Global Cryptocurrency Benchmarking Study. SSRN Electronic Journal. https://doi.org/10.2139/ssrn.2965436.

Hyde, J. (2014). Gender Similarities and Differences. Annual Review Of Psychology, 65(1): 373-398. https://doi.org/10.1146/annurev-psych-010213-115057.

Hyde, K. (2000). Recognising deductive processes in qualitative research. Qualitative Market Research: An International Journal, $3(2)$ : https://doi.org/10.1108/13522750010322089.

ING Bank. (2018). Cracking the Code on Cryptocurrency. Accessed July 6, 2021. https://think.ing.com/reports/cracking-the-code-on-cryptocurrency/.

Jain, R. (2021). Janet Yellen's proposal for a capital gains tax in US may push global money towards markets like India. Business Insider. Accessed July 7, 2021. https://www.businessinsider.in/finance/news/janet-yellens-proposal-for-a-capital-gainstax-in-us-may-push-global-money-towards-markets-like-india/articleshow/81171983.cms.

Johnson, K., \& Krueger, B. (2021). Who Supports Using Cryptocurrencies and Why Public Education About Blockchain Technology Matters? Public Administration And Information Technology, 127-149. https://doi.org/10.1007/978-3-030-55746-1_6.

Johnston, A. (2014). Rigour in research: theory in the research approach. European Business Review, 26(3): 206-217. https://doi.org/10.1108/ebr-09-2013-0115.

Kaskaloglu, K. (2014). Near zero bitcoin transaction fees cannot last forever. In The International Conference on Digital Security and Forensics (DigitalSec2014. Digitalsec. Accessed July 7, 2021. http://sdiwc.net/digital-library/near-zero-bitcoin-transactionfees-cannot-lastforever.html. 
Khan, I., Hameed, Z., \& Khan, S. (2017). Understanding Online Banking Adoption in a Developing Country. Journal of Global Information Management, 25(1): 43-65. https://doi.org/10.4018/jgim.2017010103.

Kim, S., Lee, S., Chi, Y., Im, E., \& Gim, G. (2018). A Study on the Factors Affecting the Intention to Payment Service Using Biometrics. International Journal Of Advanced Science And Technology, 114: 69-80. https://doi.org/10.14257/ijast.2018.114.07.

Kovach, S. (2021). Tesla buys $\$ 1.5$ billion in bitcoin, plans to accept it as payment. CNBC. Accessed July 7, 2021. https://www.cnbc.com/2021/02/08/tesla-buys-1point5-billion-inbitcoin.html.

Krause, M., \& Tolaymat, T. (2018). Quantification of energy and carbon costs for mining cryptocurrencies. Nature Sustainability, 1(11): 711-718. https://doi.org/10.1038/s41893018-0152-7.

Krombholz, K., Judmayer, A., Gusenbauer, M., \& Weippl, E. (2017). The Other Side of the Coin: User Experiences with Bitcoin Security and Privacy. Financial Cryptography And Data Security, 555-580. https://doi.org/10.1007/978-3-662-54970-4_33.

Krosnick, J., \& Fabrigar, L. (1997). Designing rating scales for effective measurement in surveys. Wiley-Interscience.

Krysik, J., \& Finn, J. (2013). Research for Effective Social Work Practice (3rd ed.). Routledge.

Kvasny, L., Joshi, K., \& Trauth, E. (2011). The influence of self-efficacy, gender stereotypes and the importance of it skills on college students' intentions to pursue IT careers. Proceedings Of The 2011 Iconference. https://doi.org/10.1145/1940761.1940831.

Lafferty, J., \& Wasserman, L. (2018). Statistical Analysis of Semi-Supervised Regression. figshare. Accessed July 7, 2021. https://kilthub.cmu.edu/articles/journal_contribution/Statistical_Analysis_of_SemiSupervised_Regression/6609878/1.

Lambert, S. (2019). Who are the $1 \%$ in Britain and are you one of them?. This is Money. Accessed July 7, 2021. https://www.thisismoney.co.uk/money/comment/article-7357395/Who-1Britain-one-them.html.

Lammer, D., Hanspal, T., \& Hackethal, A. (2019). Who Are the Bitcoin Investors? Evidence from Indirect Cryptocurrency Investments. SSRN Electronic Journal. https://doi.org/10.2139/ssrn.3501549.

Landry, B., Griffeth, R., \& Hartman, S. (2006). Measuring Student Perceptions of Blackboard Using the Technology Acceptance Model. Decision Sciences Journal Of Innovative Education, 4(1): 87-99. https://doi.org/10.1111/j.1540-4609.2006.00103.x.

Lee, N., \& Lings, I. (2008). Doing Business Research A Guide to Theory and Practice. Sage.

Lin, H. (2004). Responses on Anonymous and Computer-Administered Survey: A Good Way to Reduce Social Desirability Effect. The 2004 Annual Meeting Of The American Psychological Association. Accessed July 7, 2021.

Lusardi, A., \& Mitchell, O. (2014). The Economic Importance of Financial Literacy: Theory and Evidence. Journal Of Economic Literature, 52(1): 5-44. https://doi.org/10.1257/jel.52.1.5.

Makanyeza, C., \& Mutambayashata, S. (2018). Consumers' acceptance and use of plastic money in Harare, Zimbabwe. International Journal Of Bank Marketing, 36(2): 379-392. https://doi.org/10.1108/ijbm-03-2017-0044. 
HOLISTICA Vol 12, Issue 2, 2021, pp.109-144

Marx, D., \& Roman, J. (2002). Female Role Models: Protecting Women's Math Test Performance. Personality And Social Psychology Bulletin, 28(9): 1183-1193. https://doi.org/10.1177/01461672022812004.

Masrom, M. (2007). Technology Acceptance Model and E-learning, 12th International Conference on Education, Sultan Hassanal Bolkiah Institute of Education, Brunei Darussalam, pp 21-24.

Mathieson, K. (1991). Predicting User Intentions: Comparing the Technology Acceptance Model with the Theory of Planned Behavior. Information Systems Research, 2(3): 173-191. https://doi.org/10.1287/isre.2.3.173.

Maylor, H. (2005). Researching business and management. Palgrave.

McMurray, A., Pace, W., \& Scott, D. (2004). Research: A Commonsense Approach. Thomson. Mendoza-Tello, J., Mora, H., Pujol-Lopez, F., \& Lytras, M. (2018). Social Commerce as a Driver to Enhance Trust and Intention to Use Cryptocurrencies for Electronic Payments. IEEE Access, 6, 50737-50751. https://doi.org/10.1109/access.2018.2869359.

Mitchell, M., \& Jolley, J. (2010). Research design explained (7th ed.). Wadsworth Cengage Learning.

Mitchell, V. (1996). Assessing the reliability and validity of questionnaires: An empirical example. Journal Of Applied Management Studies, 5(2): 199-207.

Mohsin, S., \& Condon, C. (2021). Bloomberg - Are you a robot?. Bloomberg.com. Accessed July 7 , 2021. https://www.bloomberg.com/news/articles/2021-02-22/yellen-favors-highercorporate-tax-capital-gains-worth-mulling.

Mooi, E., \& Sarstedt, M. A Concise Guide to Market Research. Springer.

Moon, Y., \& Hwang, J. (2018). Crowdfunding as an Alternative Means for Funding Sustainable Appropriate Technology: Acceptance Determinants of Backers. Sustainability, 10(5): 1456. https://doi.org/10.3390/su10051456.

Morris, M., \& Dillon, A. (1997). How user perceptions influence software use. IEEE Software, 14(4): 58-65. https://doi.org/10.1109/52.595956.

Niglas, K. (2010). The Multidimensional Model of Research Methodology: An Integrated Set of Continua. SAGE Publications.

Oliver, P. (2010). The student's guide to research ethics (2nd ed.). Open University Press.

Oppenheim, A. (1992). Questionnaire design, interviewing and attitude measurement. Continuum.

Pallant, J. (2010). SPSS survival manual (4th ed.). Open University Press/McGraw-Hill.

Parment, A. (2013). Generation Y vs. Baby Boomers: Shopping behavior, buyer involvement and implications for retailing. Journal Of Retailing And Consumer Services, 20(2): 189199. https://doi.org/10.1016/j.jretconser.2012.12.001.

Patton, M. (2002). Two Decades of Developments in Qualitative Inquiry. Qualitative Social Work, 1(3): 261-283. https://doi.org/10.1177/1473325002001003636.

Pham, G. (2011). Radical innovation and open innovation. Diplomica Verlag.

Powell, M., \& Ansic, D. (1997). Gender differences in risk behaviour in financial decision-making: An experimental analysis. Journal Of Economic Psychology, 18(6): 605-628. https://doi.org/10.1016/s0167-4870(97)00026-3.

Puspitasari, N., Firdaus, M., Haris, C., \& Setyadi, H. (2019). An Application of the UTAUT Model for Analysis of Adoption of Integrated License Service Information System. Procedia Computer Science, 161: 57-65. https://doi.org/10.1016/j.procs.2019.11.099.

Robson, C. (2002). Real World Research: A Resource for Social Scientists and Practitioner Researches (2nd ed.). Oxford. 
Rose, S., Spinks, N., \& Canhoto, A. (2015). Management Research: Applying the Principles. Routledge.

Rosic, A. (2021). Smart Contracts: The Blockchain Technology That Will Replace Lawyers. Blockgeeks. Accessed July 6, 2021. https://blockgeeks.com/guides/smart-contracts/.

Rubin, A., \& Babbie, E. (2010). Essential research methods for social work (2nd ed.). Cengage Learning.

Salisbury, W., Pearson, R., Pearson, A., \& Miller, D. (2001). Perceived security and World Wide Web purchase intention. Industrial Management \& Data Systems, 101(4): 165-177. https://doi.org/10.1108/02635570110390071.

Saunders, M., Lewis, P., \& Thornhill, A. (2012). Research methods for business students (6th ed.). Pearson.

Saunders' Research Onion. (2015). [Image]. Accessed July 7, 2021. https://www.researchgate.net/figure/The-Research-onion-Source-Saunders-et-al2012_fig9_281004945.

Schaupp, L., \& Festa, M. (2018). Cryptocurrency adoption and the road to regulation. Proceedings Of The 19Th Annual International Conference On Digital Government Research: Governance In The Data Age. https://doi.org/10.1145/3209281.3209336.

Sekaran, U., \& Bougie, R. (2009). Research Methods for Business: A Skill Building Approach. John Wiley \& Sons.

Shahzad, F., Xiu, G., Wang, J., \& Shahbaz, M. (2018). An empirical investigation on the adoption of cryptocurrencies among the people of mainland China. Technology In Society, 55: 33-40. https://doi.org/10.1016/j.techsoc.2018.05.006.

Shaikh, A., Glavee-Geo, R., \& Karjaluoto, H. (2018). How Relevant Are Risk Perceptions, Effort, and Performance Expectancy in Mobile Banking Adoption? International Journal Of E-Business Research, 14(2): 39-60. https://doi.org/10.4018/ijebr.2018040103.

Sheau-Fen, Y., Sun-May, L., \& Yu-Ghee, W. (2012). Store Brand Proneness: Effects of Perceived Risks, Quality and Familiarity. Australasian Marketing Journal, 20(1): 48-58. https://doi.org/10.1016/j.ausmj.2011.10.014.

Sieverding, M., \& Koch, S. (2009). (Self-)Evaluation of computer competence: How gender matters. Computers \& Education, 52(3), 696-701. https://doi.org/10.1016/j.compedu.2008.11.016

Simonite, T. (2011). What Bitcoin Is, and Why It Matters. MIT Technology Review. Accessed July 7 , 2021. https://www.technologyreview.com/s/424091/what-bitcoin-is-and-why-it-matters/.

Sirkin, R. (2006). Statistics for the social sciences. Sage Publications.

Sood, A., \& Tellis, G. (2005). Technological Evolution and Radical Innovation. Journal Of Marketing, 69(3): 152-168. https://doi.org/10.1509/jmkg.69.3.152.66361.

State of Crypto: 2021 UK Report I Gemini. Gemini. (2021). Accessed July 7, 2021. https://www.gemini.com/state-of-uk-crypto.

Statista. (2021). Gender Population of UK [Image]. Accessed July 7, 2021. https://www.statista.com/statistics/281240/population-of-the-united-kingdom-uk-bygender/>.

Statista | UK: mobile phone ownership 1996-2018. Statista. (2021). Accessed July 7, 2021. https://www.statista.com/statistics/289167/mobile-phone-penetration-in-the-uk/.

Stinerock, R., Stern, B., \& Solomon, M. (1991). Sex and money: Gender differences in the use of surrogate consumers for financial decision-making. Services Marketing Quarterly, 7(2): 167182. https://doi.org/10.1080/15332969.1991.9985022.

Stolper, O., \& Walter, A. (2017). Financial literacy, financial advice, and financial behavior. Journal Of Business Economics, 87(5): 581-643. https://doi.org/10.1007/s11573-017-0853-9. 
HOLISTICA Vol 12, Issue 2, 2021, pp.109-144

Ten years after the genesis block, bitcoin's been captured by the system it was supposed to replace. The Verge. (2021). Accessed July 2021. https://www.theverge.com/2019/1/3/18166096/bitcoin-blockchain-code-currencymoney-genesis-block-silk-road-mt-gox.

The Theory of Planned Behaviour. (2014). [Image]. Accessed July 7, 2021. https://www.researchgate.net/figure/The-Theory-of-Planned-Behavior-ModelTPB_fig2_262794302.

The UTAUT Model. (2015). [Image]. Accessed July 7, 2021. https://www.researchgate.net/figure/The-research-model-UTAUT-Venkatesh-et-al-2003The-UTAUT-model-uses-four-core_fig1_283503814.

Tourangeau, R., Edwards, B., Johnson, P., Wolter, K., \& Bates, N. (2014). Hard-to-Survey Populations. Cambridge: Cambridge University Press.

Tran, V. (2009). Pocket Guide to Developing Cross-Cultural Measurement in Social Work Research and Evaluation (2nd ed.). Oxford University Press.

Types of cryptocurrencies: explaining the major types of cryptos. Capital.com. (2019). Accessed July 7, 2021. https://capital.com/types-of-cryptocurrencies.

van Rooij, M., Lusardi, A., \& Alessie, R. (2011). Financial literacy and stock market participation. $\begin{array}{llll}\text { Journal Of Financial } & \text { 449-472. }\end{array}$ https://doi.org/10.1016/j.jfineco.2011.03.006.

Vekiri, I., \& Chronaki, A. (2008). Gender issues in technology use: Perceived social support, computer self-efficacy and value beliefs, and computer use beyond school. Computers \& Education, 51(3): 1392-1404. https://doi.org/10.1016/j.compedu.2008.01.003.

Venkatesh, Morris, Davis, \& Davis. (2003). User Acceptance of Information Technology: Toward a Unified View. MIS Quarterly, 27(3): 425. https://doi.org/10.2307/30036540.

Wegner, T. (2007). Applied Business Statistics: Methods and Excel-Based Applications (2nd ed.). Juta.

Williams, M., Rana, N., \& Dwivedi, Y. (2015). The unified theory of acceptance and use of technology (UTAUT): a literature review. Journal Of Enterprise Information Management, 28(3): 443-488. https://doi.org/10.1108/jeim-09-2014-0088.

Wilson, J. (2014). Essentials of Business Research: A guide to doing your research project. Sage Publications.

Zhang, Y. (2000). Using the Internet for survey research: A case study. Journal Of The American Society For Information Science, 51(1): 57-68. https://doi.org/10.1002/(sici)10974571(2000)51:1<57::aid-asi9>3.0.co;2-w.

Zinkhan, G., \& Karande, K. (1991). Cultural and Gender Differences in Risk-Taking Behavior among American and Spanish Decision Makers. The Journal Of Social Psychology, 131(5): 741-742. https://doi.org/10.1080/00224545.1991.9924657. 


\section{Appendix \\ Pilot questionnaire feedback examples}

Questionnaire Feedback

Thank you for taking part in the pilot study of my research, it was appreciated deeply. Now could you please take some time to provide any feedback so that it can be improved.

\begin{tabular}{|c|c|}
\hline Questions & Comments \\
\hline $\begin{array}{l}\text { 1. How long did it take you to } \\
\text { complete the questionnaire? }\end{array}$ & About 5 minutes \\
\hline 2. Was it difficult to complete? & Not at all, very easy to read and simple journey \\
\hline $\begin{array}{c}\text { 3. If there were any unclear or } \\
\text { ambiguous questions, please state } \\
\text { now. }\end{array}$ & $\begin{array}{l}\text { The one that asked whether cryptocurrencies will } \\
\text { improve individual aspects could have been better } \\
\text { worded }\end{array}$ \\
\hline $\begin{array}{l}\text { 4. Did you feel uneasy answering any } \\
\text { questions? If yes, which ones. }\end{array}$ & Felt comfortable answering all questions \\
\hline $\begin{array}{l}\text { 5. In your opinion, did you feel any } \\
\text { major topics were left out? }\end{array}$ & No \\
\hline $\begin{array}{c}\text { 6. Was the layout clear and } \\
\text { aesthetic? }\end{array}$ & $\begin{array}{l}\text { Layout and journey very clear, aesthetic was basic but } \\
\text { that's fine }\end{array}$ \\
\hline 7. Any additional comments? & No \\
\hline
\end{tabular}

\section{Questionnaire Feedback}

Thank you for taking part in the pilot study of my research, it was appreciated deeply. Now could you please take some time to provide any feedback so that it can be improved.

\begin{tabular}{|c|c|}
\hline Questions & Comments \\
\hline $\begin{array}{l}\text { 1. How long did it take you to complete the } \\
\text { questionnaire? }\end{array}$ & Between 5-10 minutes \\
\hline 2. Was it difficult to complete? & $\begin{array}{l}\text { Nope, easy to complete as was all to do with } \\
\text { my own opinions }\end{array}$ \\
\hline $\begin{array}{l}\text { 3. If there were any unclear or ambiguous } \\
\text { questions, please state now. }\end{array}$ & Nope all seemed fine to me \\
\hline $\begin{array}{l}\text { 4. Did you feel uneasy answering any } \\
\text { questions? If yes, which ones. }\end{array}$ & No question made me feel uneasy \\
\hline $\begin{array}{l}\text { 5. In your opinion, did you feel any major } \\
\text { topics were left out? }\end{array}$ & $\begin{array}{l}\text { I wouldn't say a major topic, but maybe ask if } \\
\text { cryptocurrencies are desirable }\end{array}$ \\
\hline 6. Was the layout clear and aesthetic? & Yes was all good \\
\hline 7. Any additional comments? & No \\
\hline
\end{tabular}




\section{Reliability testing using SPSS}

Figure 13 Intention

\begin{tabular}{c|c|r}
\multicolumn{3}{c}{ Reliability Statistics } \\
& $\begin{array}{c}\text { Cronbach's } \\
\text { Alpha Based } \\
\text { on }\end{array}$ & \\
$\begin{array}{c}\text { Cronbach's } \\
\text { Alpha }\end{array}$ & $\begin{array}{c}\text { Standardized } \\
\text { Items }\end{array}$ & N of Items \\
\hline .834 & .827 & 3 \\
\hline
\end{tabular}

Source: SPSS, 2021.

Figure 14 Performance expectancy

\begin{tabular}{c|c|c}
\multicolumn{3}{c}{ Reliability Statistics } \\
$\begin{array}{c}\text { Cronbach's } \\
\text { Alpha Based } \\
\text { on }\end{array}$ \\
$\begin{array}{c}\text { Cronbach's } \\
\text { Alpha }\end{array}$ & $\begin{array}{c}\text { Standardized } \\
\text { Items }\end{array}$ & N of Items \\
\hline .940 & .941 & 3 \\
\hline
\end{tabular}

Source: SPSS, 2021.

Figure 15 Effort expectancy

\begin{tabular}{c|c|c}
\multicolumn{3}{c}{ Reliability Statistics } \\
$\begin{array}{c}\text { Cronbach's } \\
\text { Alpha Based } \\
\text { on }\end{array}$ \\
$\begin{array}{c}\text { Cronbach's } \\
\text { Alpha }\end{array}$ & $\begin{array}{c}\text { Standardized } \\
\text { Items }\end{array}$ & N of Items \\
\hline .887 & .889 & 4 \\
\hline
\end{tabular}

Source: SPSS, 2021.

Figure 16 Financial and technological knowledge

Reliability Statistics

\begin{tabular}{|c|c|c|}
\hline $\begin{array}{l}\text { Cronbach's } \\
\text { Alpha }\end{array}$ & $\begin{array}{c}\text { Cronbach's } \\
\text { Alpha Based } \\
\text { on } \\
\text { Standardized } \\
\text { Items }\end{array}$ & $\mathrm{N}$ of Items \\
\hline .768 & .768 & 4 \\
\hline
\end{tabular}

Source: SPSS, 2021. 
HOLISTICA Vol 12, Issue 2, 2021, pp.109-144

Figure 17 Attitude

\begin{tabular}{c|c|c}
\multicolumn{3}{c}{ Reliability Statistics } \\
$\begin{array}{c}\text { Cronbach's } \\
\text { Cronbach's } \\
\text { Alpha Based } \\
\text { on }\end{array}$ & $\begin{array}{c}\text { Standardized } \\
\text { Items }\end{array}$ & N of Items \\
\hline .915 & .916 & 4 \\
\hline
\end{tabular}

Source: SPSS, 2021.

Figure 18 Test of normality

\begin{tabular}{|c|c|c|c|c|c|c|}
\hline \multicolumn{7}{|c|}{ Tests of Normality } \\
\hline & \multicolumn{3}{|c|}{ Kolmogorov-Smirnov ${ }^{a}$} & \multicolumn{3}{|c|}{ Shapiro-Wilk } \\
\hline & Statistic & df & Sig. & Statistic & df & Sig. \\
\hline Attitude & .118 & 102 & .001 & .962 & 102 & .005 \\
\hline Int & .086 & 102 & .061 & .966 & 102 & .010 \\
\hline
\end{tabular}

Source: SPSS, 2021. 